\title{
Word Association Responses in L1 and L2 to the Chinese Word Yueliang (Moon): Implications for L2 Vocabulary Instruction
}

\author{
Wenying Jiang \\ Lecturer in Chinese \\ School of Languages and Cultures \\ University of Queensland \\ St. Lucia, QLD 4072, Australia
}

\begin{abstract}
A mental lexicon refers to the stored knowledge of vocabulary in one's mind. Representation of the mental lexicon is usually obtained through a word association test. A majority of the literature in mental lexicon studies has employed such word association test and focused on the response types to compare mental lexicons in first language (L1) and second language (L2) through responses to stimulus words. This study investigates the response types and detailed response items in Chinese L1 and L2 by focusing on one stimulus word yueliang, which means 'moon' in English. The findings lend support to the semantic view among the three standpoints presented (semantic, syntactic and phonological) that L2 mental lexicon might be mainly organized by semantic links. The detailed response items in Chinese L1 and L2 have been carefully studied and implications for L2 vocabulary instruction have also been discussed.
\end{abstract}

Keywords: Chinese, Mental lexicon, Word association, Foreign/second language (L2)

\section{Introduction}

A mental lexicon refers to the stored knowledge of vocabulary in one's mind. A majority of the literature in mental lexicon studies has employed a word association test for data collection and concentrated on the response types to compare mental lexicons in first language (L1) and second language (L2) through the comparison of participants' responses. In a mental lexicon, words are regarded as coexisting in an elaborate network of associations rather than being stored in separate compartments. When a word is used, the activation in the mental lexicon spreads over this network of associations. Therefore, a word is not only associated with meanings, it is also associated with other words (Wolter, 2001).

As an interconnected system, a mental lexicon is typically explored through a word association test, which involves subjects under test producing the word or words that first present themselves to their minds as being associated with a particular stimulus word (Wilks \& Meara, 2002; Wilks et al., 2005; Wolter, 2001). This approach is driven by the belief that association behaviour can reveal information about the development, structure and dynamic organization of the mental lexicon in either L1 or L2 or both. Knowledge of similarities or differences between the dynamic organization of L1 and L2 mental lexicons is crucial in understanding the acquisition process of L2 vocabulary and in designing pedagogy to effectively teach L2 vocabulary. The comparison of Chinese L1 and L2 mental lexicons based on their word association responses, in particular when contrasted with the existing knowledge of English languagebased L1 versus L2 mental lexicons, will contribute to a new understanding of mental lexicon in general given that the Chinese language is intrinsically different from English.

\section{Review of recent studies on L1 and L2 mental lexicons}

\subsection{Three response types obtained in word association tests}

A majority of the literature in mental lexicon studies, which employ word association test, concentrate on the response types to stimulus words. According to Wolter (2001), researchers are concerned with three types of responses: paradigmatic, syntagmatic, and phonological or 'clang'. Paradigmatic responses are words from the same word class as the stimulus word, and, as such, could presumably perform the same grammatical function within a given sentence. There are four main types of paradigmatic association responses, including coordinates (e.g., the prompt word chair eliciting a response table), superordinates (chair $\rightarrow$ furniture), subordinates (chair $\rightarrow$ wheelchair), and synonyms (chair $\rightarrow$ chairperson). 
Syntagmatic responses, by contrast, bear a sequential or collocational relationship to the prompt word, and, as such, are usually (but not always) from a different part of speech compared with the prompt word (rose $\rightarrow$ grow or wither). Phonological or clang responses are defined as responses that resemble the prompt word only phonologically, and bear no overt semantic connection to the prompt word (rose $\rightarrow$ chose or dog $\rightarrow$ bog).

Studies (e.g. Brown and Berko, 1960; Ervin, 1961; Entwisle, 1966; and later Palermo, 1971) show that the patterns of response type for native English-speaking school children (L1) demonstrated a tendency to produce a higher proportion of paradigmatic responses during their language development process, which is referred to as the syntagmaticparadigmatic shift. Piper and Leicester (1980) found the same shift pattern in Japanese ESL learners (L2) when their proficiency increased. Söderman (1993) investigated four groups of Finnish and Swedish learners of ESL at different stages in their experience of studying English. It was found that the mean number of paradigmatic responses was also positively related to proficiency as defined by enrolment status in the university curriculum. This finding of syntagmatic-paradigmatic shift is based on English as the target language. With Chinese as the target language, a nonalphabetic language with a writing system usually termed as logography and verbs typically using the same form for different tenses and aspects, it is reasonable to cast some doubts for a similar finding.

\subsection{Three standpoints on the organization of $L 2$ mental lexicon}

The major difference between children's L1 and adults' L2 acquisitions is that the former develops hand in hand with their cognition while the latter develops with the assistance of their L1. Due to this difference, many researchers have tried to investigate whether L1 and L2 mental lexicons are organized similarly or differently. Given that there are a large number of words in the working lexicon and word retrieval is usually fast and fluent, there must be some systematic way in organizing all the words in the mental lexicon. However, so far no consistent conclusion has been reached in terms of what plays the most important role in organizing L1 and L2 mental lexicons. Wang et al. (2010) have summarized three standpoints on what plays a major role in organizing L2 mental lexicon in comparison with L1 mental lexicon. The three standpoints, namely phonology, semantics and syntax, are discussed briefly below.

\subsubsection{Phonological standpoint}

According to the phonological standpoint, the L2 lexicon is organised primarily on a phonological basis. Meara (1982, 1984) provides the most important evidence supporting this view. Drawing on the results of a series of word association tests known collectively as the Birkbeck Vocabulary Project, Meara (1984) claimed that "there are good reasons for believing that there might be significant differences between the lexicon of a learner and that of a native speaker" (p. 231). He then concluded (1984) that "Phonology appears to play a much more prominent organizing role in the L2 mental lexicon than it does in the L1 mental lexicon" (p. 233). Although this phonological view has had wide currency, several shortcomings of the original research have been noted (Singleton, 1999), such as few genuine clang responses and failure to replicate (O'Gorman, 1996).

\subsubsection{Semantic standpoint}

The semantic standpoint holds that semantics play a predominating role in organizing L2 mental lexicon. The evidence to this view is that L2 learners also produce a high proportion of paradigmatic responses in word association tests just as native speakers do. O'Gorman (1996) and Singleton (1999) are among the many researchers who support this view. Now the belief that both L2 and L1 mental lexicons are semantically organized is gradually becoming more accepted by researchers (Wang et al., 2010).

\subsubsection{Syntactic standpoint}

The syntactic view claims that syntagmatic relations with each other mainly organize words in L2 mental lexicon. That is to say words in L2 mental lexicon are mainly linked sequentially or in a collocational manner. Wolter (2001) who studied 13 Japanese English learners and 9 native speakers first advanced this view. In his study, Wolter (2001) proposed a depth of word knowledge model of the mental lexicon, which argued that L2 mental lexicon is composed of words with varying degrees of knowledge: from core to periphery layers are well-known words, fairly well-known words, moderately known words and slightly known words. Based on this model, he found that semantic connections played a more important role in organizing words in L1 mental lexicon while syntagmatic connections played a more important role in organizing words in L2 mental lexicon. However, Wolter (2001) emphasized that "there is very little empirical evidence to support the notion that the syntactically dominated mental lexicon observed in the non-native speakers investigated in this study could not function on the same level as a paradigmatically dominant one" (p.63). Zareva's (2007) data also suggest that differences in the organization of lexical knowledge between L1 and L2 users are quantitative rather than qualitative. 
The above inconsistent conclusions arrived at may also be due to the target language developmental features in L2 acquisition or due to the similarities and differences between the L1 and L2 studied. Given that the existing body of research investigating the organizations of L1 and L2 mental lexicons has mainly used English as the target language, it is important and necessary that a different target language, for example, Chinese be investigated. Currently, little research has been done with the Chinese language either as L1 or as L2. In the face of the contradictory findings mentioned above, it may be useful therefore, to strip away the assumptions which existing studies have encouraged us to make and focus on the fundamental activity of a word association task to investigate a language that is intrinsically different from English, namely the Chinese language.

\section{The Study}

\subsection{Objective and research questions}

This study focuses on one Chinese word yueliang (月亮), which means moon in English, as a stimulus to investigate its responses by L1 and L2 language users. It is a word consisting of two characters, with the first (yue 月) meaning "month" and the second (liang 亮) meaning "bright" in Chinese. When the two characters are combined together as an independent word yueliang (月亮), it means 'moon'. Although the Chinese word yueliang and the English word moon share the same denotative meaning that refers to the natural satellite of the earth and chiefly visible at night by reflected light from the sun, their connotative meanings are quite different, which can be seen later from the word association responses by using yueliang as a stimulus word.

The word yueliang is chosen because it is a common word in both Chinese and English. Through a Google search, the Chinese word yueliang (月亮) triggered “About 132,000,000 results (0.44 seconds)" while moon triggered "About 1,650,000,000 results (0.70 seconds)" (Author, 2019). Native speakers of Chinese and English, nevertheless, may have different knowledge of the word in their respective mental lexicons. By focusing on one stimulus word, this study aims to investigate the details of association responses as well as association types. Previous studies all employed a number of stimuli words, which made it impossible to explore the detailed response items for each stimulus word. Examining the detailed response items of a stimulus word is of great value because the associated words themselves are equally important as the association types because simply categorizing all the response items into three types might have simplified the more complicated nature of mental lexicon (Kudo \& Thagard, 1999; Lü, 2010). Although detailed response items of a single stimulus word may not be able to provide a comprehensive picture for mental lexicon in general (in fact, no single study can), they certainly will provide valuable information on how L1 and L2 Chinese mental lexicons in terms of yueliang may look like.

In sum, this study aims to examine the association types and the detailed response items by L1 and L2 language users using word association test on one stimulus word yueliang. In so doing, it seeks to answer two principal research questions:

(1) What proportion will each of the three response types be in L1 and L2 Chinese?

(2) How do the detailed response items in L1 and L2 Chinese relate to each other?

\subsection{Participants}

Two groups of undergraduate students participated in this study. L1 group ( $\mathrm{n}=30,14$ male and 16 female) consisted of Chinese undergraduates from Beijing Normal University in China who majored in psychology while L2 group ( $\mathrm{n}=25$, 11 male and 14 female) consisted of English-speaking students of Chinese with high-intermediate proficiency from the University of Alberta in Canada. The age range for both groups was 19 to 23.

\subsection{Data collection procedure}

As mentioned earlier, the stimulus was one Chinese word yueliang, which means 'moon' in English. In order to better capture the participants' rich association network, this study adopted a word association test requiring multiple responses, namely, three words. Usually multiple responses are opted when the number of stimulus words is low and a single associated word is required when the number of stimulus word is high. A written-written mode was employed, namely, participants were requested to produce three words in Chinese by writing on a worksheet provided, on which both the characters and pinyin ${ }^{1}$ of yueliang were written. For both L1 and L2, the author's colleagues provided a hard copy of the worksheet, namely a word association test, to each of the participants in class in December 2016.

\footnotetext{
${ }^{1}$ Pinyin is the official Chinese phonetic system used in the People's Republic of China. It is the standard system of Romanized spelling for transliterating Chinese characters. It was used hand in hand with characters for each stimulus word in the word association test in order to facilitate $L 2$ learners of Chinese to recognize its meaning.
} 
Participants were allowed sufficient time for completing the word association test, in which yueliang was one of the stimulus words. The L2 group were instructed to use Chinese characters preferably although pinyin or English were allowed when they had difficulty to respond in Chinese characters.

\subsection{Data treatment}

All the data sheets received from both groups were numbered. Then the three response words or phrases from each participant, no matter in Chinese characters, pinyin or English, were tabulated in a Table (see Table 3 in Appendix). The content of this table was then translated into English for subsequent analysis and is presented in Table 4 (see Appendix). All the response items were categorized as paradigmatic, syntagmatic or phonological types of responses as defined in section 2.1 of this paper. Criteria used in categorizing the response items are based on the four detailed rules identified by Wolter (2001, p.52). The total number and percentage of each response types for each group of participants have been calculated and summarised in Table 1 below. The response items elicited from the two groups and the response type and frequency of occurrences of these items are presented in Table 2 in ranked order of occurrence frequency for analysis and comparison.

\section{Results}

Table 1 shows the response types with percentages in L1 and L2 for the Chinese word yueliang.

Table 1: Response types in L1 and L2 to the Chinese word yueliang

\begin{tabular}{lll}
\hline Types & L2 & L1 \\
Paradigmatic & $61 / 75=81 \%$ & $71 / 90=79 \%$ \\
Syntagmatic & $14 / 75=19 \%$ & $19 / 90=21 \%$ \\
Phonological & 0 & 0 \\
\hline
\end{tabular}

As shown in Table 1 above, only two types of responses were found in the response items, namely paradigmatic and syntagmatic. No phonological or clang type of items was found. Among the response items, paradigmatic ones comprise $81 \%$ for L2 participants and $79 \%$ for L1 group while syntagmatic ones comprise $19 \%$ for L2 participants and $21 \%$ for L1 group. The percentages of the two types of responses are quite similar for both L1 and L2 groups. Based on the response types and percentages shown in Table 1, the following can be concluded to answer the first research question: (a) No phonological or clang type of responses was found at all; (b)The percentages of paradigmatic and syntagmatic types of responses for L1 and L2 groups are quite similar; (c) For both L1 and L2 groupts, paradigmatic type (roughly 80\%) of responses was much higher than syntagmatic type (roughly 20\%) in percentage.

To answer the second research question, Table 2 below shows the detailed response items in L1 and L2 to the Chinese word yueliang.

Table 2 Detailed response items in $\mathrm{L} 1$ and $\mathrm{L} 2$ to the Chinese word yueliang

\begin{tabular}{lll|lll}
\hline L2 & & & L1 & & \\
\hline Item & Type & Frequency & Item & Type & Frequency \\
\hline star & $\mathrm{P}^{2}$ & 11 & Chang'e & $\mathrm{P}$ & 10 \\
night & $\mathrm{P}$ & 10 & moon cake & $\mathrm{P}$ & 5 \\
Apollo 11 & $\mathrm{P}$ & 6 & star & $\mathrm{P}$ & 5 \\
moonlight & $\mathrm{P}$ & 5 & missing home & $\mathrm{S}$ & 4 \\
light & $\mathrm{P}$ & 5 & Li Bai & $\mathrm{P}$ & 4 \\
sky & $\mathrm{P}$ & 5 & eclipse of the Moon & $\mathrm{P}$ & 3 \\
bright & $\mathrm{S}$ & 4 & hometown & $\mathrm{P}$ & 3 \\
darkness & $\mathrm{P}$ & 4 & moonlight & $\mathrm{P}$ & 3 \\
Neil Armstrong & $\mathrm{P}$ & 4 & night & $\mathrm{P}$ & 3 \\
sun & $\mathrm{P}$ & 4 & reunion & $\mathrm{P}$ & 3 \\
moon cake & $\mathrm{P}$ & 3 & the Mid-Autumn Festival & $\mathrm{P}$ & 3
\end{tabular}

\footnotetext{
${ }^{2} \mathrm{P}$ stands for paradigmatic and S stands for syntagmatic.

${ }^{3}$ Chang'e: the Chinese Goddess of the Moon; Li Bai: name of a well-known Chinese poet in the Chinese Tang dynasty who wrote poems about the Moon; The Wolfman: name of a movie; Chan Juan: metaphor of the Moon; Su Shi: name of a well-known Chinese poet in the Chinese Tang dynasty who also wrote poems about the Moon; Wu Gang: a character in a Chinese myth who lives on the Moon; Yu Pan: metaphor of the Moon.
} 


\begin{tabular}{|c|c|c|c|c|c|}
\hline pretty & $\mathrm{S}$ & 3 & The Wolfman & $\mathrm{P}$ & 3 \\
\hline white & $\mathrm{S}$ & 2 & sun & $\mathrm{P}$ & 2 \\
\hline bigger and bigger & $S$ & 1 & attractive & $S$ & 1 \\
\hline far & $S$ & 1 & beauty & $\mathrm{P}$ & 1 \\
\hline cheese & $\mathrm{P}$ & 1 & beloved ones & $\mathrm{P}$ & 1 \\
\hline going to the Moon & $S$ & 1 & bow & $\mathrm{P}$ & 1 \\
\hline month & $\mathrm{P}$ & 1 & Chan Juan & $\mathrm{P}$ & 1 \\
\hline reflect & $S$ & 1 & change & S & 1 \\
\hline rocket & $\mathrm{P}$ & 1 & cold & S & 1 \\
\hline round & $\mathrm{S}$ & 1 & fantasy & $\mathrm{P}$ & 1 \\
\hline stone & $\mathrm{P}$ & 1 & gentle & S & 1 \\
\hline & & & harvest & $\mathrm{P}$ & 1 \\
\hline & & & have a walk & S & 1 \\
\hline & & & hug & S & 1 \\
\hline & & & loss & $\mathrm{P}$ & 1 \\
\hline & & & lunar calendar & $\mathrm{P}$ & 1 \\
\hline & & & mysterious & S & 1 \\
\hline & & & night sky & $\mathrm{P}$ & 1 \\
\hline & & & outer space & $\mathrm{P}$ & 1 \\
\hline & & & perfect & S & 1 \\
\hline & & & poem & $\mathrm{P}$ & 1 \\
\hline & & & regretful & $S$ & 1 \\
\hline & & & rabbit & $\mathrm{P}$ & 1 \\
\hline & & & $\begin{array}{l}\text { raise my cup to toast with the } \\
\text { Moon }\end{array}$ & S & 1 \\
\hline & & & romantic & S & 1 \\
\hline & & & sad & $S$ & 1 \\
\hline & & & serenity & $\mathrm{P}$ & 1 \\
\hline & & & ship & $\mathrm{P}$ & 1 \\
\hline & & & silent & $\mathrm{S}$ & 1 \\
\hline & & & silver colour & $\mathrm{P}$ & 1 \\
\hline & & & solitary & $\mathrm{P}$ & 1 \\
\hline & & & spaceship & $\mathrm{P}$ & 1 \\
\hline & & & steamed bread & $\mathrm{P}$ & 1 \\
\hline & & & Su Shi & $\mathrm{P}$ & 1 \\
\hline & & & the Moon satellite & $\mathrm{P}$ & 1 \\
\hline & & & celestial palace & $\mathrm{P}$ & 1 \\
\hline & & & Wu Gang & $\mathrm{P}$ & 1 \\
\hline & & & wish each other a long life & $\mathrm{S}$ & 1 \\
\hline & & & younger sister & $\mathrm{P}$ & 1 \\
\hline & & & Yu Pan & $\mathrm{P}$ & 1 \\
\hline Number of item: 22 & & $22 / 75=29 \%$ & Number of item: 52 & & $52 / 90=57 \%$ \\
\hline
\end{tabular}

As shown in Table 2, the L1 responses are not only heavily culture-loaded (e.g. Chang'e, the Chinese Goddess of the Moon, appeared 10 times) but also have more items, namely the range is much larger than that of the L2. Specifically, there were 52 different items out of 90 responses for L1 versus 22 different items out of 75 responses for L2. Thus, the ratios of different items among the responses were 29\% (22/75) for the L2 group and 57\% (51/90) for the L1 group. The higher this ratio is, the richer the mental lexicon is considered to be.

In comparing the response items in L1 and L2, it is found that five items, namely star, night, sun, moonlight and moon cake, overlap in both L1 and L2 with different frequency of occurrences. The L2 response items to yueliang obtained in this study seems being much influenced by participants' L1, namely English, because Apollo 11 and Neil Armstrong are typical associations of the Moon in the English-speaking culture. It appears that L2 participants regarded yueliang as a celestial body only that seems devoid from any Chinese cultural elements apart from the fact that three L2 participants mentioned "moon cake". 
Another important finding is that both L1 and L2 groups responded with multi-word expressions. Among the 22 response items in L2 group, 5 were multi-word expressions. They occurred 15 times. Among the 52 response items in L1 group, 23 were multi-word expressions. They occurred 48 times. This phenomenon should have our attention.

\section{Discussion}

\subsection{Interpretation of findings}

The first finding of this study is that no phonological or clang type of responses emerged. This could be due to the specific language features of Chinese. A Chinese word can have one or multiple characters. According to the Frequency Dictionary of Modern Chinese (FDMC, 1986), among the top 9,000 most frequently used words, 26.7\% are unigrams or single character words , 69.8\% are bigrams (two-character words), and $2.7 \%$ are trigrams, $0.007 \%$ 4grams, and $0.0002 \%$ 5-grams. Each character contains three linguistic components: sound, shape, and meaning. To learn a character, one has to master these three components. In a study investigating Japanese text comprehension by Chinese and non-Chinese background learners focusing on Kanji, namely the Chinese characters, Machida (2001) found "both the Chinese and non-Chinese background subjects relied more on logographical coding than phonological coding to access lexicon" (p. 113). This may suggest that Chinese words in mental lexicon are not organized on a phonological basis. However, Lǘs (2010) study did find that L2 learners of Chinese responded with phonological responses for unfamiliar stimulus words, less familiar stimulus words and familiar stimulus words. In addition, the more unfamiliar of the stimulus words, the higher proportion of phonological responses was found. The author of the current study suspects that Lǘs (2010) finding might be attributed somewhat by her data collection mode as she used aural-oral mode in data collection, namely participants listened to pre-recorded reading of the stimulus words and responded orally. There was time pressure involved because 10 seconds were provided for participants to respond orally. Any responses that were beyond the 10 seconds were regarded as invalid. Receiving stimulus words aurally tend to trigger phonological responses, particularly when time pressure was involved and when participants were not sure which word they heard. In contrast, the current study used written-written data collection mode, namely participants were provided with stimulus words in written form and they were also requested to produce their responses in written form. There was no time pressure involved either. This could be the reason why no phonological type of responses was found either in L1 or L2 groups in this study. It seems that the way of receiving stimulus words plays a crucial role in producing what types of responses, particularly the phonological ones.

The second finding is that the percentages of paradigmatic and syntagmatic types of responses for L1 and L2 groups are similar. This finding supports Zareva's (2007) argument that L2 mental lexicon of a non-native speaker is structurally similar to that of a native speaker. The high percentages of paradigmatic responses in both groups $(81 \%$ versus 79\%) lend support to the semantic view that both Chinese L1 and L2 mental lexicons may be mainly semantically organized. Due to the fact the L2 group comprised learners of Chinese with relatively low level of proficiency (high-intermediate as typically classified in North American and Australian universities) and paradigmatic responses already comprised $81 \%$, it can be inferred that there is unlikely a tendency of syntagmatic-paradigmatic shift in Chinese L2 mental lexicon development.

The third finding is that a number of multi-word expressions occurred in both groups including well-known names, phrases and collocations. It was clearly instructed in the word association test worksheet that "Please list three individual words that occur to you when you read each of the following stimulus words". Participants could not help providing multi-word items. It seems that stimulus words each elicited concepts rather than individual words. For example, the names such Neil Armstrong, Li Bai, Shu Shi, each referred to a person. The phrase "moon cake" refers to the specific and symbolic food the Chinese people have when they celebrate the Moon Festival.

It is common sense that native speakers usually have a larger store of words in the mental lexicon than that for L2 learners. Therefore, it is only natural to find that the range of Chinese L1 response items is larger than that of L2 in this study. The range of Chinese L2 response items to yueliang is not only found to be smaller than that of L1, it is also much influenced by learners' mother tongue, English. Both Söderman's (1993) and Wolter's (2001) studies indicate that the dependence on the L1 mental lexicon for organizing the L2 mental lexicon tends to decrease as learners gain in proficiency. However, it is likely that the organization of the L2 mental lexicon of even highly proficient L2 learners is still influenced by their L1 mental lexicon, particularly with culturally loaded words like yueliang. This study confirms this point by demonstrating that the response items by Chinese L2 learners were very different from those by Chinese L1 speakers. The most outstanding difference lies in the fact that the L1 responses reveal the Chinese cultural elements for celebrating the Moon Festival that is for family reunion. There are many well-known poems about the moon in Chinese because the moon is symbolic and figurative in the Chinese culture. It is a symbol of beauty, romance, and fullness. 
It is not difficult to understand that more than half of the Chinese L1 response items to yueliang are culturally loaded. For example, 10 out of the $30 \mathrm{~L} 1$ participants (one thirds) responded with the Chinese Goddess of the Moon Chang'e. Other culturally loaded items include names of well-known poets who wrote about the Moon like Li Bai and SuShi, the Mid-Autumn Festival (or the Moon Festival) for family reunions in China, and metaphors of the Moon like Chan Juan and $Y u$ Pan.

In contrast, the L2 response items seem much influenced by the learners' own L1, namely English. This finding supports Fitzpatrick and Izura's (2011) conclusion that L2 associations are mediated through their L1 translation equivalents. This study demonstrates how the response items by Chinese L2 learners are influenced by their L1, namely English, as shown in Table 2. The occurrence ratio of proper names Apollo 11 and Neil Armstrong comprise $13 \%$ (10/75). Three L2 participants responded with moon cake, which indicates that L2 learners could acquire cultural information in learning vocabulary although it seems rare and sporadic.

\subsection{Implications for $L 2$ vocabulary instruction}

A good command of a new language involves the dexterous use of the acquired words of the target language. In other words, the mental lexicon, the dynamic organization of words in the mind, is the backbone of language ability. Akbarian (2010) states that "vocabulary is one of the most essential components of language learning" (p. 391). Scholars in the field of vocabulary learning and teaching have made a distinction between two dimensions of vocabulary knowledge: size and depth (Akbarian, 2010; Bogaards and Laufer, 2004; Haastrup and Henriken, 2000; Milton, 2009; Read, 2000). Size of vocabulary knowledge refers to the number of words that language learners know at a particular level of language proficiency (Akbarian, 2010; Nation, 2001). Depth of vocabulary knowledge refers to how well the language learner knows a word (Read, 1993, 2000). The word association responses to yueliang in L1 and L2 obtained in this study in a way can be used as a measure of the depth of vocabulary knowledge mastered by the studied L2 learners and L1 speakers.

The differences between the response items in L1 and L2 to the Chinese word yueliang clearly show that the connotations of yueliang in Chinese are very different from the connotations of moon in English. It is reasonable to assume that the majority of response items by L2 learners were based on their L1 mental lexicon of the word moon in English. This leads to the assumption that this heavily culture-loaded Chinese word yueliang was learnt by simply being translated into moon in English, although correct, can be inadequate or even misleading. Results in Table 2 demonstrate that L2 learners mainly treated yueliang as a celestial body as the word moon does for English-speakers. The most commonly associated words or items were 'star', 'night', 'Apollo 11', 'moonlight', 'light', 'sky', 'bright', 'darkness', 'Neil Armstrong' and 'sun' making up 77\% (58/75) of the total number of responses. These 10 words occupy $45.5 \%$ (10/22) of the different response items. Nevertheless, 'moon cake' did appear three times. This was attributed to the fact that in association with yueliang, the teacher of this group of L2 learners talked about the Chinese Mid-Autumn Festival in class and mentioned that people in China usually have moon cakes at this important occasion. This type of cultural information seems highly useful for L2 learners to build up a network of links for the target word as well as strengthening the retention of the word itself. Therefore, such practice of integrating culture in language teaching should be encouraged.

Researchers and L2 teachers all believe that culture should be integrated in L2 teaching, but which part of culture should be taught? Without specifying the exact content, culture teaching remains as empty words. It is proposed that culture teaching should be integrated in vocabulary teaching. The typical L1 response items to a stimulus word should be included as cultural knowledge in L2 vocabulary instruction to that particular word. It is recommended that designing appropriate pedagogy based on the L1 responses in teaching culturally-loaded words such as yueliang in Chinese as a foreign language (CFL) classroom should be considered. Otherwise, it may be difficult for L2 learners of Chinese to attain a depth of understanding of culturally-loaded words such as yueliang to the depth held by L1. As demonstrated in the L1 responses to yueliang, native speakers of Chinese commonly associated yueliang with 'Chang'e' (the Chinese Goddess of the Moon), 'moon cake', 'star', 'missing home', 'Li Bai' (a well-known Chinese poet in the Tang dynasty who wrote poems about the Moon and homesickness), 'eclipse of the moon', 'hometown', 'moonlight', 'night' and 'reunion', which are the top ten items in Table 2. This is because in the Chinese culture the changes of the Moon from being a crescent to a full moon symbolize the changes in one's life. A crescent can symbolize separation of family members while a full moon symbolizes reunion of family members. The Chinese MidAutumn Festival, the fifteenth day of the eighth month according to the Chinese lunar calendar, is a full moon occasion, which reminds people of family reunion like the Christmas in the West. Those who cannot get together with their families will feel homesick. Likewise, metaphors of the Moon such as Chan Juan and $Y u$ Pan, mythical characters like $W u$ Gang who is believed to live on the Moon, and popular verses such as "raise my cup to toast with the Moon" constitute the main part of the connotations for yueliang in L1. 
There is no doubt that an appreciation of the L1 detailed response items to a stimulus word is helpful in teaching the word in an L2 classroom. Nevertheless, not all the L1 response items are stable associations. Some associations may be short-term in nature. They may wax and wane with current news and cultural events. An example is the term 'The Wolfman'. This is the name of a movie with the theme of a night with full moon, which was on show in China at the time the word association test for L1 group was conducted. This item appeared in the L1 responses because some of the L1 participants saw the movie not long ago when the data were collected. Such an association is transitory as it is unlikely to be retained in the vocabulary of the language for any significant length of time after the showing of the movie ceased. Nor would people who have not seen the movie associate yueliang with The Wolfman. It is recommended that the more permanent associations be distinguished with such transitory ones among the L1 responses. The teaching of L2 vocabulary should focus on associations of more permanent in nature as transitory associations will not stand up to the test of time.

\section{Conclusion}

This study used the administration of a word association test with one stimulus word yueliang to Chinese L1 and L2 groups of participants to investigate the response types and detailed response items by both cohorts. The main findings are: (1) the percentages of paradigmatic and syntagmatic types of responses for L1 and L2 groups were found similar with high percentages (around 80\%) of paradigmatic responses by both groups; (2) no phonological response type occurred in either L1 or L2 group; (3) a number of multi-word expressions occurred in both groups. (4) five response items, namely star, night, sun, moonlight and moon cake, co-occurred in both L1 and L2 groups with different frequency of occurrences; (5) the L1 responses were not only heavily culturally-loaded but also larger in range than those of the L2; and (6) the L2 responses were highly influenced by participants' L1 word knowledge. These findings lend support to the semantic view that L2 mental lexicon is mainly organized by semantic links. Based on the responses by Chinese L1 and L2 language users to the word yueliang, it is recommended that designing appropriate pedagogy based on L1 word association responses be considered in teaching culture-loaded words like yueliang in the Chinese as a foreign language classroom in order to make teaching culture more manageable for L2 vocabulary instruction.

\section{References}

Akbarian, I. (2010). The relationship between vocabulary size and depth for ESP/EAP learners. System, 38, 39-401.

Bogaards, P. and Laufer, B. (2004). Vocabulary in a Second Language. John Benjamins Publishing Company, Amsterdam.

Brown, R. and Berko, J. (1960). Word associations and the acquisition of grammar. Child Development, 3, 1-14.

Channell, J. (1990).Vocabulary acquisition and the mental lexicon. In J. Tomasczyk and B. LewandowskaTomasczyk (Eds.), Meaning and lexicography (pp. 21-31). Amsterdam: Benjamins.

Entwisle, D. R. (1966). Word associations of young children. Baltimore: Johns Hopkins University Press.

Ervin, S. (1961). Changes with age in the verbal determinants of word association. American Journal of Psychology, 74, 361-372.

FDMC (1986). Xiandai Hanyu Pinlü Cidian (Frequency Dictionary of Modern Chinese). Beijing: Beijing Language Institute Press.

Fitzpatrick, T. and Izura, C. (2011). Word association in L1 an L2: An exploratory study of response types, response times, and interlingual mediation. Studies in Second Language Acquisition, 33, 373-398.

Haastrup, K. and Henriksen, B. (2000). Vocabulary acquisition: acquiring depth of knowledge through network building. International Journal of Applied Linguistics, 10, 221-240.

Jiang, W. (2019). A Google search for 月亮 (yueliang, which means moon in English) Retrieved "About $132,000,000$ results ( 0.44 seconds)" while moon triggered "About 1,650,000,000 results ( 0.70 seconds)" on 20 March 2019.

Lü, C. (2010). The effects of work-knowledge depth, part of speech, and proficiency level on word association among learners of Chinese as a second language. In M. E. Everson and H. H. Shen (Eds.), Research among learners of Chinese as a foreign language (Chinese Language Teachers Association Monograph Series, Vol. 4). Honolulu: University of Hawai'i, National Foreign Language Resource Center, 67-91.

Machida, S. (2001). Japanese text comprehension by Chinese and non-Chinese background learners. System, 29, 103118.

Meara, P. (1982). Word association in a foreign language: A report on the Birkbeck Vocabulary Project. Nottingham Linguistic Circular, 11, 29-37.

Meara, P. (1984). The study of lexis in interlanguage. In A. Davies, A. Howart and C. Criper (Eds.), Interlanguage (pp. 225-235). Edinburgh: Edinburgh University Press. 
Milton, J. (2009). Measuring Second Language Vocabulary Acquisition. Multilingual Matters, Bristol, England.

Palermo, D. S. (1971). Characteristics of word association responses obtained from children in grades one through four. Developmental Psychology, 5, 118-123.

Piper, T. H. and Leicester, P. F. (1980). Word association behavior as an indicator of English language proficiency. In Educational Resources Information Center (ERIC) Documents [online]. Available: Accession number ED 227651.

Read, J. (2000). Assessing Vocabulary. Cambridge: Cambridge University Press.

Söderman, T. (1993). Word associations of foreign language learners and native speakers: the phenomenon of shift of response type and its relevance for lexical development. In H. Ringbom (ed.), Near-native proficiency in English (pp. 98-182). Abo, Finland: Abo Akademi.

Singleton, D. (1999). Exploring the second language mental lexicon. Cambridge: Cambridge University Press.

Wang, H., Bing, W. and Hou, Y. (2010). A comparison study on word association between English native speakers and Chinese English learners. Canadian Social Science, 6 (6), 45-60.

Wilks, C. and Meara, P. (2002). Untangling word webs: graph theory and the notion of density in second language word association networks. Second Language Research, 18 (4), 303-324.

Wilks, C., Meara, P. and Wolter, B. (2005). A further note on simulating word association behaviour in a second language. Second Language Research, 21 (4), 359-372.

Wolter, B. (2001). Comparing the L1 and L2 Mental Lexicon: A depth of individual word knowledge model. Studies in Second Language Acquisition, 23, 41-69.

Zareva, A. (2007) Structure of the second language mental lexicon: how does it compare to native speakers' lexical organization? Second Language Research, 23 (2), 123-153.

\section{Appendices}

Table 3 Response items triggered by yueliang from both L2 learners and L1 speakers

\begin{tabular}{|c|c|c|}
\hline Participant & Words from L2 participants & Words from L1 participants \\
\hline 1 & 月光、晚上、反射 & 月饼、嫦娥、飞船 \\
\hline 2 & 星星、晚上、光 & 馒头、弓、船 \\
\hline 3 & 星星、登月, Apollo 11 & 太阳、星星、黑夜 \\
\hline 4 & 明亮、夜晚、黑天 & 月光、夜空、失落 \\
\hline 5 & 奶酪、星星、月饼 & 诗、狼人、幻想 \\
\hline 6 & 光亮、星星、天黑 & 寂胗、柔和、迷人 \\
\hline 7 & 美丽、夜晚、亮光 & 嫦娥、月饼、宁静 \\
\hline 8 & 星星、月饼、晚上 & 丰收、嫦娥、苏轼 \\
\hline 9 & 天空、月光、Neil Armstrong & 思乡、月食、李白 \\
\hline 10 & 明亮、星星、太阳 & 嫦娥、团圆、飞 \\
\hline 11 & 天空、晚上、星星 & 故乡、团聚、亲人 \\
\hline 12 & 太阳、星星、白色 & 太空、月饼、嫦娥 \\
\hline 13 & 越来越大、漂亮、Apollo 11 & 李白、月光、嫦娥 \\
\hline 14 & 光、亮、晚上 & 李白、月食、农历 \\
\hline 15 & 天空、晚上、星星 & 美女、嫦娥、悲伤 \\
\hline 16 & 月光、太阳光、黑天 & 团圆、美满、缺憾 \\
\hline 17 & 光、圆形、遥远 & 思乡、寂静、神秘 \\
\hline 18 & 白色、明亮、Apollo 11 & 月球、太阳、婵娟 \\
\hline 19 & 天空、星星、黑天 & 清冷、狼人、玉盘 \\
\hline 20 & 月光、月饼、漂亮 & 星星、吴刚、银色 \\
\hline 21 & 夜晚、月份、Apollo11 & 月饼、中秋节、变化 \\
\hline 22 & 天空、Neil Armstrong, Apollo 11 & 浪漫、思乡、散步 \\
\hline 23 & Neil Armstrong, 石头、火箭 & 狼人、拥抱、李白 \\
\hline 24 & 星星、月光、Apollo 11 & 月饼、月食、月光 \\
\hline 25 & 晚上、太阳、 Neil Armstrong & 嫦娥、夜晚、天宫 \\
\hline 26 & & 中秋节、妹妹、兔子 \\
\hline 27 & & 中秋节、嫦娥奔月、家乡 \\
\hline 28 & & 美丽的夜晚、星星、嫦娥 \\
\hline 29 & & 但愿人长久、思乡、星星 \\
\hline 30 & & 家乡、举杯邀明月、星星 \\
\hline
\end{tabular}


Table 4 English translated version of Table 3

\begin{tabular}{|c|c|c|}
\hline Participant & Words from L2 participants & Words from L1 participants \\
\hline 1 & moonlight, night, reflect & moon cake, Chang'e, spaceship \\
\hline 2 & star, night, light & steamed bread, bow, ship \\
\hline 3 & star, going to the Moon, Apollo 11 & sun, star, dark night \\
\hline 4 & bright, night, darkness & moonlight, night sky, loss \\
\hline 5 & cheese, star, moon cake & poem, The Wolfman, fantasy \\
\hline 6 & light, star, darkness & solitary, gentle, attractive \\
\hline 7 & pretty, night, light & Chang'e, moon cake, serenity \\
\hline 8 & star, moon cake, night & harvest, Chang'e, Su Shi \\
\hline 9 & sky, moonlight, Neil Armstrong & missing home, eclipse of the Moon, Li Bai \\
\hline 10 & bright, star, sun & Chang'e, reunion, fly \\
\hline 11 & sky, night, star & hometown, reunion, loved ones \\
\hline 12 & sun, star, white & outer space, moon cake, Chang'e \\
\hline 13 & bigger and bigger, pretty, Apollo 11 & Li Bai, moonlight, Chang'e \\
\hline 14 & Light, bright, night & $\mathrm{Li} \mathrm{Bai}$, eclipse of the Moon, lunar calendar \\
\hline 15 & sky, night, star & beauty, Chang'e, sad \\
\hline 16 & moonlight, sun, darkness & reunion, perfect, regretful \\
\hline 17 & light, round, far & missing home, silent, mysterious \\
\hline 18 & white, bright, Apollo 11 & The Moon as a satellite, sun, Chan Juan \\
\hline 19 & sky, star, dark & cold, The Wolfman, Yu Pan \\
\hline 20 & moonlight, moon cake, pretty & star, Wu Gang, silver colour \\
\hline 21 & night, months, Apollo11 & moon cake, the Mid-Autumn Festival, change \\
\hline 22 & sky, Neil Armstrong, Apollo 11 & romantic, missing home, have a walk \\
\hline 23 & Neil Armstrong, stone, rocket & The Wolfman, hug, Li Bai \\
\hline 24 & star, moonlight, Apollo 11 & moon cake, eclipse of the Moon, moonlight \\
\hline 25 & night, sun, Neil Armstrong & Chang'e, night, celestial palace \\
\hline 26 & & $\begin{array}{l}\text { the Mid-Autumn Festival, younger sister, } \\
\text { rabbit }\end{array}$ \\
\hline 27 & & $\begin{array}{l}\text { the Mid-Autumn Festival, Chang'e flying to } \\
\text { the Moon, hometown }\end{array}$ \\
\hline 28 & & beautiful night, star, Chang'e \\
\hline 29 & & wish each other a long life, missing home, star \\
\hline 30 & & $\begin{array}{l}\text { Hometown, raise my cup to toast with the } \\
\text { Moon, star }\end{array}$ \\
\hline
\end{tabular}

